\title{
Cognitive and neural consequences of memory suppression in major depressive disorder
}

\author{
Matthew D. Sacchet ${ }^{1,2,3}$ • Benjamin J. Levy ${ }^{3,4}$ - J. Paul Hamilton ${ }^{3,5}$. \\ Arkadiy Maksimovskiy $^{3,6}$ • Paula T. Hertel ${ }^{3,7}$ • Jutta Joormann ${ }^{3,8}$. \\ Michael C. Anderson ${ }^{3,9}$ • Anthony D. Wagner ${ }^{1,2,3}$ • Ian H. Gotlib I,2,3 $^{\text {1, }}$
}

Published online: 20 September 2016

(C) The Author(s) 2016. This article is published with open access at Springerlink.com

\begin{abstract}
Negative biases in cognition have been documented consistently in major depressive disorder (MDD), including difficulties in the ability to control the processing of negative material. Although negative information-processing biases have been studied using both behavioral and neuroimaging paradigms, relatively little research has been conducted examining the difficulties of depressed persons with inhibiting the retrieval of negative information from long-term memory. In this study, we used the think/no-think paradigm and functional magnetic resonance imaging to assess the cognitive and neural consequences of memory suppression in individuals diagnosed with depression and in healthy controls. The participants showed typical behavioral forgetting effects, but contrary to our hypotheses, there were no differences between the depressed and nondepressed participants or between neutral and negative memories. Relative to controls, depressed individuals exhibited greater activity in right middle frontal gyrus
\end{abstract}

Matthew D. Sacchet and Benjamin J. Levy contributed equally to this work.

Electronic supplementary material The online version of this article (doi:10.3758/s13415-016-0464-x) contains supplementary material, which is available to authorized users.

Matthew D. Sacchet

msacchet@stanford.edu

Neurosciences Program, Stanford University, Stanford, CA, USA

2 Department of Psychology, Stanford University, Jordan Hall, Building 01-420, 450 Serra Mall, Stanford, CA 94305, USA

3 Translational Research Center for TBI and Stress-Related Disorders (TRACTS), VA Boston Healthcare System, Boston, MA, USA

4 Department of Psychology, University of San Francisco, San Francisco, CA, USA during memory suppression, regardless of the valence of the suppressed stimuli, and differential activity in the amygdala and hippocampus during memory suppression involving negatively valenced stimuli. These findings indicate that depressed individuals are characterized by neural anomalies during the suppression of long-term memories, increasing our understanding of the brain bases of negative cognitive biases in MDD.

Keywords Major depressive disorder (MDD) · Functional magnetic resonance imaging (fMRI) · Memory suppression · Think/No-Think $($ TNT) $\cdot$ Cognitive neuroscience $\cdot$ Negative valence

Cognitive theories of major depressive disorder (MDD) suggest that negatively biased cognitive processes play a critical
5 Center for Social and Affective Neuroscience, Department of Clinical and Experimental Medicine, Linköping University, Linköping, Sweden

6 Department of Behavioral Neuroscience, Boston University School of Medicine, Boston, MA, USA

7 Department of Psychology, Trinity University, San Antonio, TX, USA

8 Department of Psychology, Yale University, New Haven, CT, USA

9 MRC Cognition and Brain Sciences Unit, University of Cambridge, Cambridge, UK 
role in the development and maintenance of depression (e.g., Beck, 1976). Negative cognitions are posited to reflect dysfunctional schemas about the self that bias individuals' processing toward negative-content stimuli. Indeed, depressed individuals exhibit enhanced memory for negative information (e.g., Mathews \& MacLeod, 2005; Matt, Vázquez, \& Campbell, 1992; Williams, Watts, MacLeod, \& Mathews, 1997) and are characterized by deficits in controlling the processing of negative material (for a review, see Gotlib \& Joormann, 2010). Theorists have suggested that these difficulties involving the processing of negative information contribute to the onset and severity of MDD (e.g., Ingram, 1984; Kircanski, Joormann, \& Gotlib, 2012; Teasdale, 1983). Therefore, it is critical that we gain a better understanding of how depressed individuals process and control negative information.

One line of research, focusing on the functioning of working memory (WM), indicates that depressed individuals are characterized by deficits in inhibitory control (Gotlib \& Joormann, 2010). For example, Joormann (2004) and Gotlib, Yue, and Joormann (2005) found that dysphoric individuals show reduced negative priming for negative stimuli; similar results were also reported by Goeleven, De Raedt, Baert, and Koster (2006) with depressed individuals. In these tasks, participants are asked to attend to, and make a judgment about, one stimulus while ignoring a second, simultaneously presented, stimulus. The negative-priming effect refers to a behavioral slowing that occurs when participants must respond to a stimulus that they were asked to ignore on the previous trial. This slowing is posited to reflect the lingering effects of inhibitory processes that were initiated when participants were required to ignore the stimulus when it was previously presented. Findings that depressed individuals show a reduced negative-priming effect for negatively valenced stimuli suggest that they have difficulty inhibiting the processing of negative items, and thus instead attend to the items they are supposed to ignore. Other studies have demonstrated that depressed individuals have difficulty removing no-longerrelevant negative information from WM (e.g., Joormann \& Gotlib, 2008; Joormann, Nee, Berman, Jonides, \& Gotlib, 2010; Levens \& Gotlib, 2010). In these experiments, participants briefly memorize two sets of words and then are immediately instructed to ignore one of the sets to make a subsequent judgment about the words. Depressed individuals have difficulty when they are required to ignore sets of negative words (Joormann \& Gotlib, 2008; Joormann et al., 2010), indicating impairment in removing negative information from WM.

Collectively, these studies indicate that depressed individuals are impaired in their ability to regulate the processing of negative stimuli. It is important to note, however, that these investigations have focused primarily on how depressed persons process novel or recently experienced information. It is likely that depressed individuals also struggle with inhibiting recall of long-term negative memories (Gotlib \& Joormann, 2010). In fact, the accessibility of negative memories and the tendency to ruminate about them are hallmark characteristics of depression (Nolen-Hoeksema, 2000). One way in which researchers have studied individuals' ability to inhibit unwanted long-term memories is by using the think/no-think (TNT) task (Anderson \& Green, 2001). In this task, individuals learn paired associates (e.g., insect-roach) and are then asked to either practice retrieving (think) or suppressing the associates (no-think). The consequences of retrieving and suppressing are then assessed with a memory test in which all the learned associations are tested, including some pairs that the participants did not retrieve or suppress after the initial learning (i.e., baseline items). In nondepressed individuals, suppressing associates results in poorer subsequent memory for those words (Anderson \& Green, 2001; for a review, see Anderson \& Hanslmayr, 2014; Anderson \& Huddleston, 2011). This finding of suppression-induced forgetting (SIF) suggests that attempting to prevent unwanted memories from entering awareness results in decreased long-term accessibility of those memories. With respect to depression, if depressed individuals have difficulty inhibiting retrieval, then they should show reduced SIF. Interestingly, the results of studies testing this formulation are mixed, with some showing that dysphoric and depressed individuals demonstrate less SIF than do healthy control participants (Hertel \& Gerstle, 2003; Hertel \& Mahan, 2008; Joormann, Hertel, Brozovich, \& Gotlib, 2005), and others reporting no differences between dysphoric or depressed individuals and controls (Hertel \& Calcaterra, 2005; Joormann, Hertel, LeMoult, \& Gotlib, 2009). In fact, averaging across these five studies (weighted by sample size) yields data indicating that whereas control participants show a SIF effect of $5 \%$ (effects that are consistent with, though slightly smaller than, those reported in other studies using unselected samples; e.g., Anderson \& Huddleston, 2011), depressed participants show a SIF effect of $0 \%$, suggesting a modest deficit in inhibitory control in depression. ${ }^{1}$

The TNT paradigm has been adapted to study brain activity when individuals attempt to inhibit memory retrieval (Anderson, 2004; Benoit \& Anderson, 2012; Butler \& James, 2010; Depue, Curran, \& Banich, 2007; Hulbert, Henson, \& Anderson, 2016; Levy \& Anderson, 2012; PazAlonso, Bunge, Anderson, \& Ghetti, 2013). These studies have indicated that suppression is associated with increased

\footnotetext{
${ }^{1}$ This only includes participants in the "unaided" condition in those studies, which was the condition most comparable to the method we used here. When provided with "aids" (i.e., alternative diversionary thoughts to think about instead of the target), both controls and MDD patients showed far stronger SIF, and differences between the groups were minimized.
} 
activity in a set of regions including lateral prefrontal cortex (both dorsal and ventral regions), medial prefrontal cortex (including the anterior cingulate cortex and presupplementary motor area), and lateral parietal cortex (including the intraparietal sulcus and angular gyrus). This network is posited to be involved in the implementation of cognitive control that allows individuals to prevent unwanted memories from entering awareness. Increased activity in this network is accompanied by a decrease in medial temporal lobe activity during suppression, which is posited to be the target of topdown inhibitory regulation (Anderson, 2004; Depue et al., 2007; for a review, see Anderson \& Hanslmayr, 2014). Consistent with this possibility, several studies have used effective connectivity analysis to document top-down modulation of hippocampal activity during retrieval suppression (Benoit \& Anderson, 2012; Benoit, Hulbert, Huddleston, \& Anderson, 2015; Gagnepain, Henson, \& Anderson, 2014). Importantly, suppression is also associated with decreased activity in the amygdala when the items being suppressed are negatively valenced, suggesting a modulation of emotional response during these experiences (Depue et al., 2007). The patterns of brain activity during suppression exhibited by these unselected samples of individuals provide a baseline for understanding impaired memory suppression in MDD.

To date, investigators have not examined the neural bases of the deficits in SIF that have been reported in depressed individuals. In the present study, we assessed both the cognitive and the neural correlates of memory suppression in depressed individuals and healthy controls. Participants first learned paired associates, in which the cue word was always neutral but the response word was either negative or neutral in valence. Next, we scanned participants as they completed the TNT phase, which required them to either retrieve or suppress some of the word-pair associates. Immediately after this phase, we tested participants' memory for all of the paired associates while they were still in the scanner. On the basis of previous findings, we hypothesized that depressed participants would exhibit less SIF than would healthy controls. We also predicted that depressed participants would have difficulty suppressing negative memories in particular, although it should be noted that prior studies using the TNT paradigm failed to confirm this prediction (Hertel \& Gerstle, 2003; Joormann et al., 2005). Consistent with previous reports of reduced cognitive control ability in depressed individuals, we further predicted that depressed participants would demonstrate less activity than would healthy controls in the recruitment of prefrontal and parietal regions during suppression attempts. Finally, we predicted that, as compared to healthy controls, depressed participants would exhibit greater activation in the hippocampus and amygdala during no-think trials, particularly when negative memories were suppressed, reflecting diminished control over these memories for depressed individuals.

\section{Method}

\section{Participants}

Nineteen healthy control (CTL) individuals and 18 individuals diagnosed with MDD participated in the study. The data from three CTL and two MDD individuals were excluded due to problems with task presentation in the scanner (MDD $N=1$, CTL $N=1$ ) or scanner function (CTL $N=1$ ), discomfort in the scanner (CTL $N=1$ ), or an inability to learn the word pairs (MDD $N=1$ ). After excluding these five participants, we were left with 16 MDD participants (nine females, seven males) and 16 CTL participants (eight females, eight males). The CTL participants had no history of psychiatric disorders and had never taken psychotropic medication. All participants were recruited through online postings, were between 18 and 56 years of age, had no history of brain injury and no substance/alcohol abuse in the last six months, and met the requirements for MRI scanning (e.g., had no metal implants). The MDD participants were not comorbid for bipolar I or II (mania), psychosis, or learning disabilities. The depressed participants also met the DSM-IV criteria for current MDD using the Structured Clinical Interview for DSM (SCID; First, Dibbon, Spitzer, \& Williams, 2004). All participants also completed the Beck Depression Inventory (Beck, Rush, Shaw, \& Emery, 1979). Participants were compensated for their time, and all gave informed consent. The study was in compliance with the ethical standards set forth by the American Psychiatric Association and was conducted with approval from the Stanford University institutional review board.

\section{Think/no-think task}

\section{Materials}

The critical stimuli for this study were 24 sets of words; each set included four words. Each set was designed to have two possible cues (e.g., Trunk or Street), both of which were neutral, and two possible response words, one of which was negatively valenced (e.g., Corpse) and the other of which had a neutral valence (e.g., Violin). These words were selected from the Affective Norms for English Words (Bradley \& Lang, 1999), allowing us to assess the valence (negative response words, $M=2.1, S D=0.5$; neutral response words, $M=5.5, S D$ $=0.6$; neutral cue words, $M=5.1, S D=0.6$ ) and arousal (negative response words, $M=5.0, S D=0.9$; neutral response words, $M=4.0, S D=1.0$; neutral cue words, $M=3.4, S D=$ 0.7 ) ratings for each set of items.

Each set was designed so the cue words would act as effective retrieval cues for either response, so that the assignments of cues to responses could be counterbalanced across participants (i.e., one participant learned Trunk-Corpse and Street-Violin, 
and another participant learned Trunk-Violin and StreetCorpse). Similarly, the assignments of words pairs to conditions (baseline, think, and no-think) were also counterbalanced across participants. This meant that there were a total of six counterbalancing conditions for the items (three conditions and two cue-to-response mappings). Importantly, the cues were always neutral; therefore, the cue itself (Trunk or Street) did not provide any information about the valence of the response word. The independent probes were also designed to uniquely cue each response word separately (e.g., Anatomy-Co__ for Corpse; Lessons-Vi__ for Violin). Independent probes are used in these type of paradigms to rule out several noninhibitory explanations of forgetting (for more information, see Anderson \& Spellman, 1995). These sets were divided into three groups of eight items that rotated through the experimental conditions (think, no-think, and baseline). An additional six word pairs (all neutral items) were used as fillers throughout the experiment; thus, each participant learned a total of 54 word pairs (six filler, eight think-negative, eight thinkneutral, eight baseline-negative, eight baseline-neutral, eight no-think-negative, and eight no-think-neutral).

\section{Procedure}

The TNT procedure consisted of three separate phases: learning, TNT, and test. The learning phase was completed outside the scanner; the TNT phase and test phase were conducted while participants were inside the bore of the MRI scanner, though fMRI data were collected only during the TNT phase. This procedure was used to minimize forgetting on the final test that might be due to changes in physical and mental context associated with getting out of the scanner.

Learning phase Participants learned the cue-associate word pairs through a drop-off study-test training procedure. On study trials, participants were presented with an intact word pair for $5 \mathrm{~s}$ and were encouraged to form an association between the items. On test trials, the cue word appeared and participants had up to $5 \mathrm{~s}$ to verbally report the associate. For feedback, the correct associate was presented for $2 \mathrm{~s}$ after every test trial. An experimenter recorded whether or not the response was correct. If no response was given or the response was incorrect, that cue word was presented again at the end of the list (i.e., items recalled correctly dropped out of the set). This was repeated for each list until every correct associate was provided once. To make this learning phase easier for participants, we divided the large number of word pairs into smaller lists and tested each word pair three times across the whole learning phase. More specifically, participants initially learned lists of six word pairs at a time (i.e., they studied six pairs, and then were immediately given drop-off testing on those six items). After the participants had learned three lists of six pairs, they were given an 18-item drop-off test covering all three lists they had just learned. Once this was complete, they moved on to three more lists of six items, followed by an 18-item drop-off test reviewing all of those pairs. After a third list of 18 items was learned, participants were given a drop-off cycle on all 54 word pairs they had learned. Once completed, participants were given one final test for all the cue-associate pairs to confirm which word pairs had actually been learned. During this last test, participants were not given feedback after making their response, and items they missed did not appear again at the end of the cycle. To minimize any potential differences in learning between the conditions (e.g., between negative and neutral items or between the MDD and CTL groups), all subsequent analyses were restricted to cue-associate pairs that were correctly reported on this final learning test. This allowed us to be sure that any differences we observed were not due to differences in initial learning.

TNT phase For each trial, participants saw a cue from one of the word pairs (e.g., Street) and were asked to exert control over the retrieval process. For think trials, they were asked to recall the associated word (e.g., Corpse). For no-think trials, their task was to prevent the associated word from entering consciousness. Participants were not given any specific suggestions about strategies they could use to accomplish this task. Each retrieval cue was presented for $3 \mathrm{~s}$, and they were asked to follow the task instructions for the entire time the cue was presented. Participants were cued to perform either of these tasks by the color of the cue word: Think cues appeared in green, and no-think cues were red. Participants completed a practice block that was 20 trials long and that included only filler pairs, to get the participants used to the procedure before scanning began. After this practice phase, they were asked about their approach to the task and given directed feedback if they were not performing the task as instructed (e.g., if they averted their gaze from the retrieval cue or covertly rehearsing the responses for no-think trials). The actual TNT phase consisted of six runs of 64 trials each (384 trials total); each run lasting $5 \mathrm{~min} 40 \mathrm{~s}$. Each cue was repeated twice during every block (eight think and eight no-think cues of both valences, each presented twice). The trial order was determined by Optseq (http://surfer.nmr.mgh.harvard.edu/optseq; Dale, 1999), which pseudorandomly mixed the four conditions (think-negative, think-neutral, no-think-negative, and nothink-neutral) and used variable intertrial intervals (0.5-12 s). During the intertrial intervals a fixation cross appeared in the center of the screen, and participants were instructed to look at the cross and wait for the next trial to begin.

Test phase After the end of MRI scanning, memory was tested for all word pairs. Participants were administered a brief practice test that tested only filler word pairs, to make sure that they understood the task. Then they were given two final memory tests, the same-probe (SP) and independent-probe 
(IP) tests, with the order of these two tests counterbalanced across participants. For each test trial, a retrieval cue was presented for $4 \mathrm{~s}$, and participants were asked to verbally provide the associated word. The retrieval cue for the SP test was the cue from the originally studied word pair, and for the IP test it was a semantically related but unstudied cue along with a twoletter stem (Fig. 1A).

\section{Behavioral measures}

The data from the test phase were analyzed to assess the behavioral consequences of attempting to control conscious awareness of a memory. A $2 \times 2 \times 2 \times 3$ mixed analysis of variance (ANOVA) was utilized, with the between-subjects factor Group (MDD and CTL) and the within-subjects factors Test Type (SP, IP), Valence (negative, neutral), and Condition (think, baseline, no-think). To focus more directly on the key behavioral measure (i.e., the magnitude of SIF), suppression scores were calculated by subtracting the recall of no-think items from the recall of baseline items, within a given valence and within each test type. This measure provides an index of how successful participants were at forgetting the avoided associates, controlling for general forgetting that would be expected on a delayed memory test. This measure treated SIF as a positive value, so participants who forgot more of the no-think items would show larger suppression scores.

\section{MRI data acquisition}

Whole-brain imaging data was acquired via a 3.0-T General Electric Signa MR scanner (Milwaukee, Wisconsin) at the Richard M. Lucas Center for Imaging at Stanford University School of Medicine. After a scout scan used for slice prescription, high-order shimming was performed for whole-brain distortion estimation until diminished returns were produced. Blood-oxygenation-level-dependent (BOLD) functional data were acquired using an eight-channel, whole-head coil from 31 axial slices with a spiral in-out pulse sequence (Glover \& Law, 2001; TR $=2,000 \mathrm{~ms}$, TE $30 \mathrm{~ms}$, flip angle $=80^{\circ}$, FOV $=$ $22 \mathrm{~cm}$, number of frames $=170$, in-plane resolution $=$ $3.44 \mathrm{~mm}^{2}$, through-plane resolution $=4 \mathrm{~mm}$ ). To anatomically localize the functional activations, a high-resolution structural scan (spoiled gradient echo: 156 slices, in-plane resolution = $0.86 \times 0.86 \mathrm{~mm}$, through-plane resolution $=1 \mathrm{~mm}, \mathrm{TE}=$ $3.4 \mathrm{~ms}$, flip angle $=15^{\circ}, \mathrm{FOV}=22 \mathrm{~cm}$ ) was collected after the BOLD scanning runs.

\begin{tabular}{|c|c|c|c|}
\hline A & Think & No-Think & Baseline \\
\hline Study Phase & $\begin{array}{l}\text { COUCH - FILTH } \\
\text { FISH - ROTTEN }\end{array}$ & $\begin{array}{l}\text { FALL - NIGHTMARE } \\
\text { MORNING - VOMIT }\end{array}$ & $\begin{array}{c}\text { SUBJECT - FAILURE } \\
\text { PHONE - RAPE }\end{array}$ \\
\hline Neutral & $\begin{array}{c}\text { RUG - WOOL } \\
\text { HARI - CUSTOM }\end{array}$ & $\begin{array}{c}\text { ERRAND - MINUTE } \\
\text { PRAIRIE - HAY }\end{array}$ & $\begin{array}{l}\text { DETAIL - METHOD } \\
\text { STREET - VIOLIN }\end{array}$ \\
\hline Think/No-Think Phase & $\mathrm{COUCH}$ & FALL & No Stimulus Presented \\
\hline Test Phase & $\mathrm{COUCH}-$ & FALL - & SUBJECT - \\
\hline Independent Probe & GRIME - FI & DREAM - NI__ & SUCCESS - FA \\
\hline
\end{tabular}

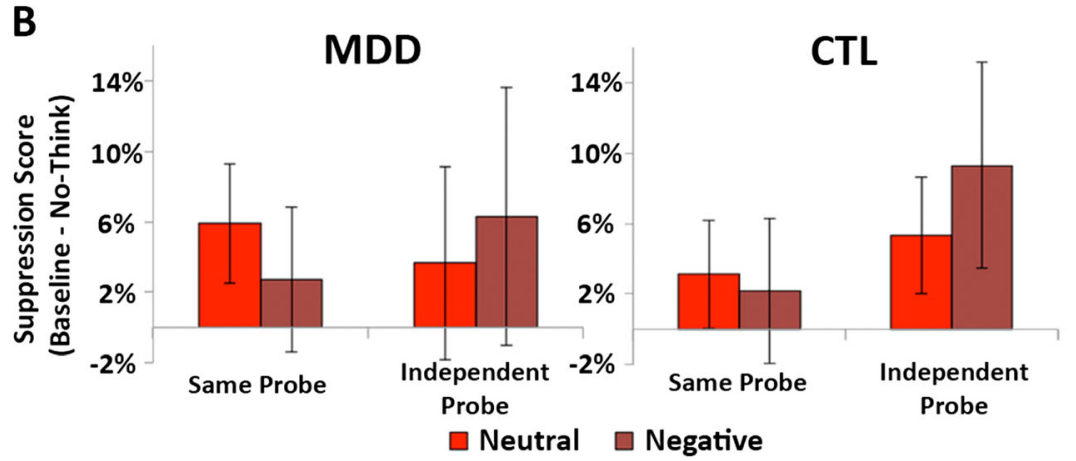

Fig. 1 Behavioral procedure (A) and results (B). (A) During the study phase, participants learned word pairs until they could provide the associated member of each pair when shown the cue word as a retrieval cue. Then, during the think/no-think (TNT) phase, participants were scanned while they tried to exert control over memory retrieval. For think trials (in green during the trial), participants were asked to think of the associated word. For no-think trials (in red), they were asked to prevent the related word from entering awareness. Baseline items were not presented during this phase. After scanning, participants were asked to recall all of the studied response words, from both the originally studied retrieval cue (the same-probe test) and from a novel, extralist associate (the independent-probe test). (B) The critical outcome measure in the TNT task was the suppression score, which reflected whether or not avoided memories were recalled more poorly than baseline items (Baseline recall - No-think recall). Shown here are the suppression scores for both groups of participants (MDD and CTL), as a function of the valence of the to-besuppressed memory (neutral or negative) and the type of final memory test (SP or IP). Overall, participants tended to forget the no-think items, and these suppression scores did not vary significantly by group, valence, or test type. The full set of means for recall in the final test phase are reported in Table 4. Error bars indicate standard errors of the means (SEMs). 


\section{FMRI data processing and analysis}

Data processing and analysis was conducted using the Analysis of Functional Neuroimages (AFNI) software suite (National Institutes of Health; http://afni.nimh.nih.gov/; Cox, 1996) and MATLAB (The MathWorks Inc., Natick, MA). The BOLD images were slice-time-corrected, followed by motion correction with a Fourier interpolation algorithm. Data were not corrected further if sudden movements were less than $1 \mathrm{~mm}$. A despiking algorithm was used to correct for movements between 1 and $3 \mathrm{~mm}$ by replacing motioninfluenced acquisitions with outlier insensitive estimates. Specifically, a given TR was defined as an outlier if its BOLD value was greater than a standard deviation threshold. Outlier values were then replaced with values from a polynomial fit across all TRs, excluding outliers. Spatial smoothing was conducted with a Gaussian kernel (full width at half maximum $=4 \mathrm{~mm}$ ). The data were high-pass filtered at $1 \mathrm{cycle} / \mathrm{min}$ and converted to percent signal change. Finally, individual participant maps were converted to the Talairach common template space (Talairach \& Tournoux, 1998), which allowed for between-group comparisons.

Processed time series data were then submitted to a general linear model (Friston, Holmes, Worsley, \& Poline, 1995) that included regressors for condition (think and no-think) and valence (negative and neutral), residual motion, and first-, second-, and third-order polynomial trends. The regressors of interest were convolved with a gamma-variate function that modeled a canonical hemodynamic response before inclusion in the model (Cohen, 1997), and betas were estimated.

To assess consistency with previous fMRI investigations of the TNT procedure (e.g., Anderson, 2004), whole-brain maps were first computed using paired $t$ tests on a voxel-wise basis, to create contrasts between think and no-think trials. This was done separately for each group (CTL and MDD) and both valences (neutral and negative). This allowed us to assess the extent to which the basic pattern of suppression-related activations would be observed in each of our contrasts (e.g., the MDD group suppressing negative items).

Next, we assessed whether activations differed between the CTL and MDD groups and between valences. To do this, we computed voxel-wise mixed ANOVAs with the betweensubjects factor Group (MDD, CTL) and the within-subjects factors Condition (think, no-think) and Valence (negative, neutral). We then tested the significance of the two-way interactions between group and condition (within neutral trials) to identify any regions that were differentially active in the MDD versus CTL groups during no-think trials. Finally, to also consider valence, we looked for any regions that showed a threeway interaction of group, condition, and valence. This allowed us to identify regions that depressed and nondepressed participants might recruit differentially during the suppression of negative material.
All of these analyses were conducted at the whole-brain level; we had strong a priori interest, however, in the hippocampus and the amygdala. Thus, for these regions, we also conducted analyses with a small-volume correction (SVC), defined by probabilistic cytoarchitecture maps derived from postmortem brains (Eickhoff et al., 2005). For a given region, a voxel was included if at least $50 \%$ of postmortem brains indicated that the voxel was identified as that region. Given that these were neighboring regions, a single search space was created for each hemisphere by combining hippocampal regions (cornu ammonis, entorhinal cortex, dentate gyrus, and subiculular complex) and amygdalar regions (centromedial, laterobasal, and superficial groups). The resulting bilateral hippocampus/amygdala volume was used for SVC, for a total volume of $23,960 \mathrm{~mm}^{3}$ (2,995 voxels). In the Results section, we report which clusters were identified in the whole-brain analysis, and which only survived using the SVC.

To control for multiple hypothesis testing while identifying significant outcomes, cluster-wise correction was implemented using 10,000 Monte Carlo simulations (Xiong, Gao, Lancaster, \& Fox, 1995) using AFNI's AlphaSim program. For whole-brain analyses, the uncorrected voxel significance threshold was set to $p=.005$, requiring a cluster of $256 \mathrm{~mm}^{3}(k$ $=32$ voxels) to reach a corrected significance level of $p<.05$. To reach a corrected $p<.05$ significance level in the SVC analysis of the combined hippocampus/amygdala, the voxelwise threshold was set to $p<.05$, and the required cluster sizes were $352 \mathrm{~mm}^{3}$ ( $k=44$ voxels) for left and $368 \mathrm{~mm}^{3}$ ( $k=$ 46 voxels) for right hippocampus/amygdala. Thus, both whole-brain and SVC analyses maintained a family-wise Type I error rate at $p<.05$. A more conservative voxel-wise $p$-value threshold was adopted for the whole-brain analysis, to reduce false positives, improve localization, and facilitate interpretation (Chrastil, Sherrill, Hasselmo, \& Stern, 2015; Woo, Krishnan, \& Wager, 2014).

To further explore significant the two- and three-way interactions involving group, time courses were extracted from significant clusters, and summary average signal estimates were computed across the second, third, and fourth time points (TRs 2-4, encompassing the expected activation peak), consistent with prior studies of the TNT paradigm (e.g., Levy \& Anderson, 2012).

\section{Correlational analyses}

Prior studies had found that behavioral measures of forgetting correlated with brain activity in the prefrontal cortex and within the medial temporal lobes (e.g., Anderson, 2004; Depue et al., 2007; Levy \& Anderson, 2012). Similarly, studies had also reported correlations between the activity in different brain regions (e.g., Anderson, 2004; Benoit \& Anderson, 2012; Depue et al., 2007), providing insights into how regions might interact during this task. Therefore, we attempted to replicate these analyses, but the analyses were inconclusive, so we report them 
Table 1 Participant demographics

\begin{tabular}{lllllr}
\hline & \multicolumn{2}{l}{ MDD } & & \multicolumn{2}{c}{ CTL } \\
\cline { 2 - 3 } \cline { 5 - 6 } & $M$ & $S D$ & & $M$ & \multicolumn{2}{c}{$S D$} \\
\hline Age (Years) & 31.5 & 8.9 & 31.7 & 10.0 \\
Education (Years) & 14.5 & 2.5 & 15.4 & 2.5 \\
BDI (Total score) & 31.1 & 9.5 & 1.8 & 2.2 \\
Female & $56.25 \%$ & & $50 \%$ & \\
\hline
\end{tabular}

$\mathrm{MDD}=$ depressed participants; $\mathrm{CTL}=$ control participants; $\mathrm{BDI}=$ Beck Depression Inventory I or II

only in the supplement (see the Supplemental Results). We also performed a series of exploratory analyses to explore whether activity in our regions of interest correlated with various clinical and psychological characteristics (see the Supplemental Method). Given the exploratory nature of these analyses, we also report the results of these analyses in the supplement (see the Supplemental Results).

\section{Results}

\section{Participant characteristics}

Demographic and clinical characteristics of the MDD and CTL participants are presented in Table 1. The depressed and nondepressed groups did not differ in age $[t(30)=0.06$, $p=.96$, years of education $[t(30)=1.08, p=.29$ ], or gender $\left[\chi^{2}(1, N=32)=0.13, p=.72\right]$. As expected, MDD participants scored higher than did CTL participants on the BDI $[t(30)=12.0, p<.01]$. Additional clinical characteristics for each of the MDD participants are presented in Table 2.

\section{Learning performance}

The drop-off learning procedure ensured that both groups of participants had learned most of the word pairs by the time they got to the last practice test (see Table 3). The CTL group recalled nonsignificantly more words $(93.9 \%)$ than did the MDD group (89.7\%) [t(30) $=1.12, p=.28]$. Similarly, the interaction between group and valence was not significant $[F(1,30)=2.07, p=.16]$. All subsequent analyses were conditionalized on learning so as to ensure that the results were not influenced by learning differences (i.e., the behavioral and neuroimaging analyses only considered data from word pairs that were correctly recalled during this final practice test).

\section{Final recall performance}

To assess the behavioral consequences of exerting control over retrieval, we investigated recall performance on the final memory test as a function of group (MDD and CTL), condition (think, baseline, and no-think), valence (negative and neutral), and test type (SP and IP; see Table 4 for the full set of means). This analysis yielded a main effect of test type $[F(1,30)=161.0, p<.001]$, reflecting better recall on the SP test $(90.9 \%)$ than on the IP test $(58.8 \%)$. This effect is

Table 2 MDD participant clinical data

\begin{tabular}{|c|c|c|c|c|c|c|}
\hline Participant & Comorbidity & $\begin{array}{l}\text { Medication (Daily Dosage } \\
\text { [mg], Duration [Months]) }\end{array}$ & $\begin{array}{l}\text { MDD-Related } \\
\text { Hospitalizations }\end{array}$ & $\begin{array}{l}\text { Current Episode } \\
\text { Duration (Months) }\end{array}$ & $\begin{array}{l}\text { Years Since First } \\
\text { Episode }\end{array}$ & $\begin{array}{l}\text { BDI } \\
\text { Score }\end{array}$ \\
\hline 1 & None & $\begin{array}{l}\text { Buprenorphine }(4,8) \text {; Zolpidem } \\
\quad(10,11)\end{array}$ & 0 & 5 & 17 & 30 \\
\hline 2 & None & None & 0 & 9 & 30 & 29 \\
\hline 3 & DYS, anxiety disorder NOS & Lorazepam $(0.5,120)$ & 1 & 8 & 45 & 22 \\
\hline 4 & Social phobia & None & 0 & N.R. & 30 & 16 \\
\hline 5 & None & None & 0 & 3 & 1 & 38 \\
\hline 6 & None & Lorazepam $(2,18)$ & 0 & 144 & 15 & 29 \\
\hline 7 & None & None & 0 & 2 & 11 & 36 \\
\hline 8 & None & $\begin{array}{l}\text { Lithium (NR, 24); Fluvoxamine } \\
\quad(300,24)\end{array}$ & 1 & 120 & 10 & 24 \\
\hline 9 & None & None & 1 & 1 & 14 & 36 \\
\hline 10 & None & None & 0 & 1 & 23 & 31 \\
\hline 11 & GAD & None & 1 & 3 & 20 & 21 \\
\hline 12 & None & Sertraline $(100,24)$ & 0 & 1 & 21 & 26 \\
\hline 13 & None & None & 0 & 3 & 23 & 54 \\
\hline 14 & None & Bupropion $(300,12)$ & 0 & 3 & 4 & 27 \\
\hline 15 & DYS & None & 0 & 2 & 10 & 32 \\
\hline 16 & None & Lithium $(600,18)$ & 0 & 192 & 16 & 46 \\
\hline
\end{tabular}

$\mathrm{MDD}$ = major depressive disorder; DYS = dysthymia; GAD = generalized anxiety disorder; N.R. = not reported; BDI = Beck Depression Inventory I or II 
Table 3 Performance on the final learning test before the TNT phase

\begin{tabular}{|c|c|c|c|c|}
\hline & \multicolumn{2}{|l|}{ MDD } & \multicolumn{2}{|l|}{ CTL } \\
\hline & $M$ & $S D$ & $M$ & $S D$ \\
\hline All associates & $89.7 \%$ & $11.2 \%$ & $93.9 \%$ & $8.3 \%$ \\
\hline Negative associates & $87.8 \%$ & $14.0 \%$ & $93.5 \%$ & $9.0 \%$ \\
\hline Neutral associates & $91.7 \%$ & $9.3 \%$ & $94.3 \%$ & $8.0 \%$ \\
\hline
\end{tabular}

$\mathrm{MDD}=$ depressed participants; $\mathrm{CTL}=$ control participants

not surprising, given that novel semantic associates typically produce poorer recall than do retrieval cues that were present at encoding (e.g., Tulving \& Thomson, 1973). The analysis also yielded a main effect of condition $[F(2,60)=3.77, p<$ $.05]$, which reflects the fact that no-think items $(71.9 \%)$ were recalled less frequently than baseline items $(76.7 \%)[F(1,30)$ $=9.88, p<.005]$, replicating the basic SIF effect (see Anderson \& Huddleston, 2011). No main effects were obtained for group or valence $(F \mathrm{~s}<1)$, and none of the possible interactions were significant.

Although the absence of any significant interactions suggests that SIF was not modulated by group or valence, a limitation of these analyses is that they also included think performance in the condition variable. Our a priori interest was specifically in differences in SIF, which is defined as the difference in recall between the no-think and baseline conditions. Therefore, we also conducted planned comparisons examining the difference between no-think and baseline suppression scores (see Fig. 1B), as a function of group and valence. Contrary to our predictions, the magnitude of these suppression scores did not interact with any combination of valence,

Table 4 Recall performance on the final memory tests (conditionalized on correct initial learning)

\begin{tabular}{|c|c|c|c|c|c|c|}
\hline & & & \multicolumn{2}{|l|}{ MDD } & \multicolumn{2}{|l|}{ CTL } \\
\hline & & & $M$ & $S D$ & $M$ & $S D$ \\
\hline \multirow[t]{6}{*}{ Same probe } & \multirow[t]{2}{*}{ Think } & Neg & $89.6 \%$ & $11.8 \%$ & $93.8 \%$ & $15.3 \%$ \\
\hline & & Neu & $94.6 \%$ & $11.6 \%$ & $97.7 \%$ & $5.0 \%$ \\
\hline & \multirow[t]{2}{*}{ No-think } & Neg & $85.6 \%$ & $16.3 \%$ & $91.1 \%$ & $12.4 \%$ \\
\hline & & Neu & $84.7 \%$ & $18.4 \%$ & $89.4 \%$ & $12.4 \%$ \\
\hline & \multirow[t]{2}{*}{ Baseline } & Neg & $88.3 \%$ & $15.2 \%$ & $93.3 \%$ & $10.6 \%$ \\
\hline & & Neu & $90.6 \%$ & $13.7 \%$ & $92.5 \%$ & $8.2 \%$ \\
\hline \multirow[t]{6}{*}{ Independent probe } & \multirow[t]{2}{*}{ Think } & Neg & $58.6 \%$ & $20.3 \%$ & $56.9 \%$ & $26.4 \%$ \\
\hline & & Neu & $61.7 \%$ & $17.2 \%$ & $54.7 \%$ & $27.9 \%$ \\
\hline & \multirow[t]{2}{*}{ No-think } & Neg & $59.7 \%$ & $18.2 \%$ & $56.4 \%$ & $22.2 \%$ \\
\hline & & Neu & $53.2 \%$ & $18.7 \%$ & $55.3 \%$ & $22.1 \%$ \\
\hline & \multirow[t]{2}{*}{ Baseline } & Neg & $66.0 \%$ & $19.7 \%$ & $65.7 \%$ & $23.1 \%$ \\
\hline & & Neu & $56.8 \%$ & $16.5 \%$ & $60.6 \%$ & $20.5 \%$ \\
\hline
\end{tabular}

$\mathrm{MDD}=$ depressed participants $; \mathrm{CTL}=$ control participants Neg $=$ negatively valenced words; $\mathrm{Neu}=$ neutral words group, or test type $\left(F_{\mathrm{S}}<1\right)$, consistent with the pattern observed in the overall ANOVA. Thus, we found no evidence of any differences in SIF as a function of the valence of the words or depression group status.

\section{FMRI results}

For the imaging results, we began by comparing the brain activity during think and no-think trials, separately for each group and each valence (see Table 5 and Fig. 2). We did this, in part, to facilitate comparisons with previous imaging studies that had used the TNT task (e.g., Anderson, 2004; Benoit et al., 2015; Butler \& James, 2010; Depue et al., 2007; Gagnepain et al., 2014; Levy \& Anderson, 2012). First, we examined CTL participants and neutral stimuli, because this condition was most comparable to those in the majority of prior studies. Importantly, we replicated the typical pattern of activity: increased activity during no-think trials in prefrontal (including inferior and middle frontal gyrus, premotor, and supplementary motor cortex) and lateral parietal cortex, along with decreased activity during no-think trials in the medial temporal lobes and medial parietal cortex. Similarly, when CTL participants engaged with negative stimuli, a condition that was explored in two prior studies (Butler \& James, 2010; Depue et al., 2007), we again replicated the patterns described above. The novelty of the present study, of course, was the inclusion of MDD participants engaged in the same task as CTL participants. Here we observed a similar pattern to that in the CTL group when depressed individuals exerted control over either neutral or negative stimuli, with all of the key patterns being replicated in these contrasts. This suggests that the basic regions involved in memory suppression are broadly similar across depression statuses and valences. This analysis was not sufficient, however, to assess whether any group- and valence-related differences would emerge in the neural aspects of memory suppression. Therefore, we conducted analyses focused on assessing whether these other factors (Group and Valence) influence brain activity during the TNT task.

To assess the differences between depressed and nondepressed individuals, we first looked for regions that showed a two-way interaction of condition (think, no-think) and depression status (MDD, CTL). We restricted this analysis to neutral items so we could focus on whether depressed and nondepressed individuals differed in how they approached the task, without considering the negative stimuli that we expected would be particularly challenging for depressed individuals. Although we found no differences in the behavioral consequences of suppression for the two groups of participants, depressed individuals might nevertheless have achieved the same outcome by recruiting different neural processes than those recruited by their nondepressed counterparts. We obtained a significant interaction of group and condition in three clusters (Table 6), two of which were located in the right middle frontal 
Table 5 Differences in brain activity between think and no-think trials, separated by group (MDD and CTL) and valence (neutral and negative)

\begin{tabular}{|c|c|c|c|c|}
\hline Laterality & Region & Max $t$ Value & $\begin{array}{l}\text { Tal L/R, A/P, } \\
\mathrm{I} / \mathrm{S}(\mathrm{mm})\end{array}$ & $\begin{array}{l}\text { Cluster Extent (voxels, } \\
1 \text { voxel }=8 \mathrm{~mm}^{3} \text { ) }\end{array}$ \\
\hline
\end{tabular}

\section{MDD Group, Neutral Items}

No-Think > Think

\begin{tabular}{|c|c|c|c|c|}
\hline $\mathrm{R}$ & Inferior frontal gyrus & 5.431 & $+53.0+17.0+4.0$ & 567 \\
\hline $\mathrm{R}$ & Premotor & 5.861 & $+5.0+11.0+58.0$ & 503 \\
\hline $\mathrm{R}$ & Middle frontal gyrus & 6.237 & $+35.0+33.0+34.0$ & 492 \\
\hline $\mathrm{R}$ & Cingulate & 5.586 & $+7.0+17.0+34.0$ & 277 \\
\hline $\mathrm{L}$ & Inferior frontal gyrus & 4.955 & $-53.0+15.0+6.0$ & 244 \\
\hline $\mathrm{L}$ & $\begin{array}{l}\text { Middle frontal gyrus/inferior } \\
\text { frontal gyrus }\end{array}$ & 4.537 & $-43.0+27.0+32.0$ & 125 \\
\hline $\mathrm{L}$ & Inferior parietal & 4.541 & $-49.0-41.0+44.0$ & 117 \\
\hline $\mathrm{L}$ & Middle frontal gyrus/frontal pole & 4.216 & $-21.0+47.0+26.0$ & 76 \\
\hline $\mathrm{L}$ & Interior temporal pole & 5.672 & $-47.0-9.0-34.0$ & 54 \\
\hline $\mathrm{L}$ & Orbitofrontal & 4.412 & $-17.0+57.0-14.0$ & 39 \\
\hline \multicolumn{5}{|c|}{ Think $>$ No-Think } \\
\hline $\mathrm{L}$ & Posterior cingulate & -7.425 & $-11.0-37.0+32.0$ & 2,201 \\
\hline $\mathrm{L}$ & Parieto-occipital & -5.161 & $-5.0-85.0+38.0$ & 796 \\
\hline $\mathrm{L}$ & Medial prefrontal & -5.479 & $-5.0+27.0+4.0$ & 418 \\
\hline $\mathrm{L}$ & Hipppocampus & -5.931 & $-23.0-33.0+4.0$ & 266 \\
\hline $\mathrm{L}$ & Parieto-occipital & -5.447 & $-45.0-65.0+24.0$ & 177 \\
\hline $\mathrm{L}$ & White matter & -6.709 & $-19.0-21.0+22.0$ & 133 \\
\hline $\mathrm{R}$ & White matter & -5.345 & $+13.0-13.0+28.0$ & 82 \\
\hline $\mathrm{R}$ & White matter & -4.323 & $+19.0-21.0+22.0$ & 75 \\
\hline $\mathrm{L}$ & White matter & -4.186 & $-31.0-57.0+8.0$ & 63 \\
\hline $\mathrm{L}$ & White matter & -5.497 & $-17.0-25.0+44.0$ & 38 \\
\hline $\mathrm{R}$ & White matter & -3.968 & $+31.0-15.0+28.0$ & 32 \\
\hline
\end{tabular}

CTL Group, Neutral Items

No-Think > Think

$\mathrm{L}$

L

L

L

$\mathrm{R}$

$\mathrm{R}$

L

R

L

$\mathrm{L}$

Think $>$ No-Think

$\mathrm{R}$

L

$\mathrm{R}$

$\mathrm{R}$

$\mathrm{R}$

$\mathrm{R}$

$\mathrm{R}$

$\mathrm{R}$

L
Inferior frontal gyrus

Inferior frontal gyrus and middle frontal gyrus

Supplementary motor area

Inferior temporal

Insula

Premotor

Inferior parietal

Temporal pole

Premotor

Cerebellum

Posterior cingulate cortex

White matter

White matter/posterior medial temporal lobe

Occipital lobe

Superior frontal gyrus

Ventral anterior cingulate

Cingulate gyrus

Frontal pole

Cerebellum
5.286

5.087

5.694

5.151

4.448

5.086

4.120

4.801

3.985

4.149

$-5.715$

$-4.515$

$-4.370$

$-5.127$

$-4.575$

$-6.545$

$-3.936$

$-4.225$

$-4.376$
Tal L/R, A/P 1 voxel $=8 \mathrm{~mm}^{3}$ )
567

503

492

277

244

125

117

76

54

39

2,201

796

418

266

177

133

75

63

32

$+31.0-15.0+28.0$

$-43.0+37.0+22.0 \quad 793$

$-39.0-1.0+46.0 \quad 735$

$-3.0+19.0+42.0 \quad 397$

$-57.0-57.0-6.0 \quad 228$

$+5.0+13.0+2.0 \quad 112$

$+13.0+9.0+60.0 \quad 99$

$-41.0-35.0+42.0 \quad 62$

$+45.0+9.0-16.0 \quad 60$

$-1.0+9.0+60.0 \quad 57$

$-33.0-51.0-26.0 \quad 39$

$+5.0-35.0+38.0 \quad 568$

$-25.0-9.0+30.0 \quad 138$

$+17.0-23.0+6.0 \quad 120$

$+13.0-89.0+0.0 \quad 108$

$+13.0+33.0+44.0 \quad 93$

$+1.0+25.0-6.0 \quad 77$

$+5.0-13.0+34.0 \quad 73$

$+3.0+61.0+14.0 \quad 69$

$-31.0-69.0-28.0 \quad 68$ 
Table 5 (continued)

\begin{tabular}{|c|c|c|c|c|}
\hline Laterality & Region & Max $t$ Value & $\begin{array}{l}\text { Tal L/R, A/P, } \\
\mathrm{I} / \mathrm{S}(\mathrm{mm})\end{array}$ & $\begin{array}{l}\text { Cluster Extent (voxels, } \\
1 \text { voxel }=8 \mathrm{~mm}^{3} \text { ) }\end{array}$ \\
\hline $\mathrm{R}$ & Inferior parietal & -3.775 & $+43.0-29.0+24.0$ & 60 \\
\hline \multicolumn{5}{|c|}{ MDD Group, Negative Items } \\
\hline \multicolumn{5}{|c|}{ No-Think $>$ Think } \\
\hline $\mathrm{R}$ & Frontal & 7.062 & $+33.0+31.0+28.0$ & 2,293 \\
\hline $\mathrm{R}$ & Premotor & 7.183 & $+7.0+13.0+54.0$ & 1,596 \\
\hline $\mathrm{L}$ & Premotor & 6.233 & $-27.0+7.0+42.0$ & 602 \\
\hline $\mathrm{L}$ & Inferior parietal & 5.426 & $-45.0-45.0+44.0$ & 373 \\
\hline $\mathrm{L}$ & Middle frontal gyrus & 7.141 & $-45.0+23.0+36.0$ & 350 \\
\hline $\mathrm{R}$ & Inferior parietal & 4.723 & $+37.0-35.0+38.0$ & 280 \\
\hline $\mathrm{L}$ & Inferior temporal gyrus & 6.470 & $-57.0-43.0-10.0$ & 253 \\
\hline $\mathrm{L}$ & Inferior frontal gyrus & 4.701 & $-49.0+17.0+4.0$ & 245 \\
\hline $\mathrm{R}$ & Inferior parietal sulcus & 5.753 & $+25.0-61.0+42.0$ & 137 \\
\hline $\mathrm{L}$ & Inferior frontal gyrus & 4.285 & $-37.0+49.0-6.0$ & 122 \\
\hline $\mathrm{L}$ & $\begin{array}{l}\text { Inferior frontal gyrus/middle } \\
\text { frontal gyrus }\end{array}$ & 4.638 & $-43.0+7.0+28.0$ & 100 \\
\hline $\mathrm{L}$ & Inferior temporal gyrus & 4.378 & $-39.0-53.0-12.0$ & 84 \\
\hline $\mathrm{R}$ & White matter & 4.021 & $+17.0-1.0+10.0$ & 66 \\
\hline $\mathrm{L}$ & Orbitofrontal & 5.357 & $-11.0+19.0-20.0$ & 48 \\
\hline $\mathrm{R}$ & Orbitofrontal & 5.116 & $+31.0+47.0-8.0$ & 43 \\
\hline $\mathrm{R}$ & Middle temporal gyrus & 4.586 & $+47.0-33.0-4.0$ & 42 \\
\hline $\mathrm{R}$ & Frontal temporal & 4.405 & $+29.0+13.0-18.0$ & 34 \\
\hline \multicolumn{5}{|c|}{ Think $>$ No-Think } \\
\hline $\mathrm{R}$ & Parietal-occipital & -6.395 & $+3.0-79.0+38.0$ & 528 \\
\hline $\mathrm{R}$ & Precuneus & -5.223 & $+15.0-55.0+24.0$ & 296 \\
\hline $\mathrm{L}$ & Precuneus & -4.217 & $-13.0-55.0+18.0$ & 195 \\
\hline $\mathrm{L}$ & Hippocampus & -5.608 & $-29.0-37.0+2.0$ & 155 \\
\hline $\mathrm{R}$ & Brainstem & -4.446 & $+5.0-35.0-38.0$ & 50 \\
\hline $\mathrm{R}$ & White matter & -4.448 & $+1.0+21.0+4.0$ & 47 \\
\hline $\mathrm{L}$ & White matter & -4.316 & $-27.0-29.0+24.0$ & 42 \\
\hline $\mathrm{L}$ & Cingulate & -3.775 & $-7.0-41.0+34.0$ & 40 \\
\hline $\mathrm{R}$ & Cerebellum & -4.987 & $+21.0-43.0-34.0$ & 36 \\
\hline $\mathrm{R}$ & White matter & -4.252 & $+17.0-37.0+6.0$ & 32 \\
\hline \multicolumn{5}{|c|}{ CTL Group, Negative Items } \\
\hline \multicolumn{5}{|c|}{ No-Think $>$ Think } \\
\hline $\mathrm{L}$ & Frontal & 5.428 & $-39.0+1.0+44.0$ & 1,209 \\
\hline $\mathrm{R}$ & $\begin{array}{l}\text { Middle frontal gyrus/superior } \\
\text { frontal gyrus }\end{array}$ & 6.080 & $+43.0-1.0+36.0$ & 817 \\
\hline $\mathrm{R}$ & Cingulate & 4.509 & $+13.0+11.0+38.0$ & 559 \\
\hline $\mathrm{L}$ & Inferior temporal & 4.953 & $-47.0-55.0-4.0$ & 495 \\
\hline $\mathrm{L}$ & Inferior Parietal & 5.432 & $-43.0-35.0+44.0$ & 420 \\
\hline $\mathrm{L}$ & $\begin{array}{l}\text { Inferior frontal gyrus/middle } \\
\text { frontal gyrus }\end{array}$ & 5.762 & $-29.0+35.0+14.0$ & 365 \\
\hline $\mathrm{R}$ & Inferior frontal gyrus & 4.875 & $+39.0+25.0+10.0$ & 300 \\
\hline $\mathrm{L}$ & Occipital & 5.662 & $-35.0-85.0+10.0$ & 206 \\
\hline $\mathrm{R}$ & Inferior parietal sulcus & 5.711 & $+25.0-57.0+44.0$ & 193 \\
\hline $\mathrm{R}$ & Middle frontal gyrus & 4.235 & $+37.0+47.0+26.0$ & 151 \\
\hline $\mathrm{L}$ & Superior parietal & 5.091 & $-17.0-67.0+54.0$ & 98 \\
\hline $\mathrm{R}$ & Inferior temporal & 4.078 & $+49.0-71.0+0.0$ & 79 \\
\hline
\end{tabular}


Table 5 (continued)

\begin{tabular}{|c|c|c|c|c|}
\hline Laterality & Region & Max $t$ Value & $\begin{array}{l}\text { Tal L/R, A/P, } \\
\mathrm{I} / \mathrm{S}(\mathrm{mm})\end{array}$ & $\begin{array}{l}\text { Cluster Extent (voxels, } \\
1 \text { voxel }=8 \mathrm{~mm}^{3} \text { ) }\end{array}$ \\
\hline $\mathrm{R}$ & Occipital & 4.845 & $+35.0-83.0+16.0$ & 65 \\
\hline $\mathrm{R}$ & Cerebellum & 3.894 & $+33.0-59.0-10.0$ & 38 \\
\hline \multicolumn{5}{|c|}{ Think $>$ No-Think } \\
\hline $\mathrm{L}$ & Cingulate & -5.841 & $-1.0-37.0+38.0$ & 457 \\
\hline $\mathrm{L}$ & White matter & -5.293 & $-33.0-31.0+4.0$ & 157 \\
\hline $\mathrm{R}$ & Precuneus & -5.519 & $+9.0-59.0+22.0$ & 152 \\
\hline $\mathrm{R}$ & Hippocampus & -4.923 & $+21.0-29.0+2.0$ & 145 \\
\hline $\mathrm{R}$ & Middle temporal gyrus & -5.633 & $+55.0-15.0-8.0$ & 122 \\
\hline $\mathrm{R}$ & Brainstem & -5.567 & $+3.0-39.0-32.0$ & 83 \\
\hline $\mathrm{R}$ & Cingulate & -4.369 & $+5.0-17.0+32.0$ & 73 \\
\hline $\mathrm{L}$ & Insula & -4.380 & $-39.0-13.0+12.0$ & 71 \\
\hline $\mathrm{R}$ & White matter & -4.789 & $+9.0+27.0+0.0$ & 55 \\
\hline $\mathrm{R}$ & Middle temporal & -3.998 & $+47.0+3.0-18.0$ & 40 \\
\hline
\end{tabular}

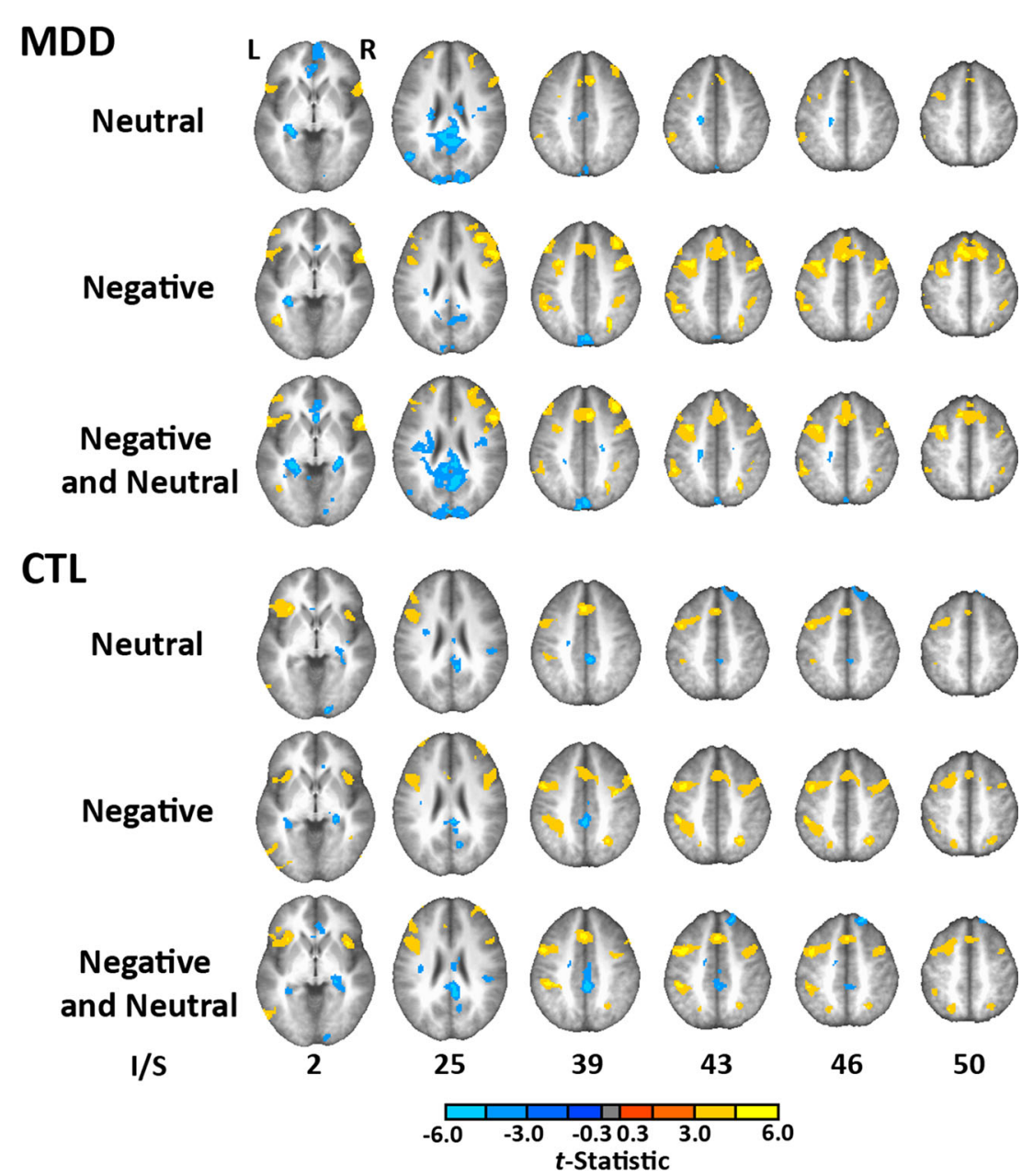

Fig. 2 Comparison of brain activity during think and no-think trials. Warm colors indicate increased activity during no-think as compared to think trials, and cool colors indicate decreased activity during no-think as compared to think trials. The top three rows depict activity for the MDD group, and the bottom three rows display data from the CTL group. Each row represents the valence of the to-be- suppressed item (neutral, negative, or collapsing across both valence types). In general, the patterns for both groups and across all combinations of valence resemble prior findings using this paradigm: No-think trials are associated with increased activity in prefrontal and parietal regions and decreased activity in the medial temporal lobes and in medial parietal regions. $\mathrm{L}=$ left, $\mathrm{R}=$ right 
Table 6 Brain regions identified by the two-way interaction of condition (Think and No-Think) and group (MDD and CTL) for neutral items only

\begin{tabular}{lllll}
\hline Laterality & Region & Max $F$ Stat & Tal L/R, A/P, I/S (mm) & $\begin{array}{l}\text { Cluster Extent (voxels, } \\
1 \text { voxel = } \text { mm }^{3} \text { ) }\end{array}$ \\
\hline $\mathrm{R}$ & MFG & 13.772 & $29,29,38$ & 137 \\
$\mathrm{~L}$ & Ventral striatum/white matter & 29.694 & $-13,-1,-6$ & 53 \\
$\mathrm{R}$ & MFG/SFG & 17.564 & $21,55,30$ & 37 \\
\hline
\end{tabular}

gyrus (MFG), a region we hypothesized might be engaged differentially by depressed and nondepressed individuals during suppression. To better understand this interaction, we extracted the time courses from the larger MFG cluster (Fig. 3).
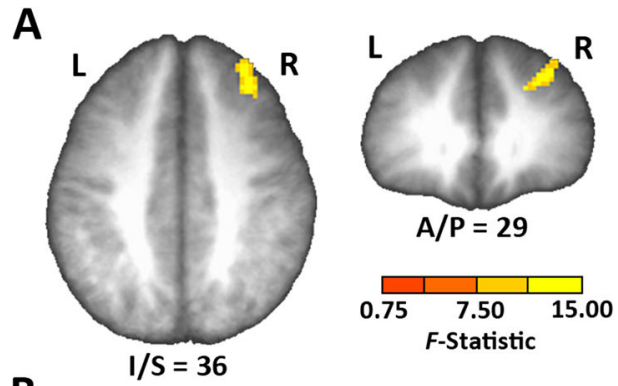

B

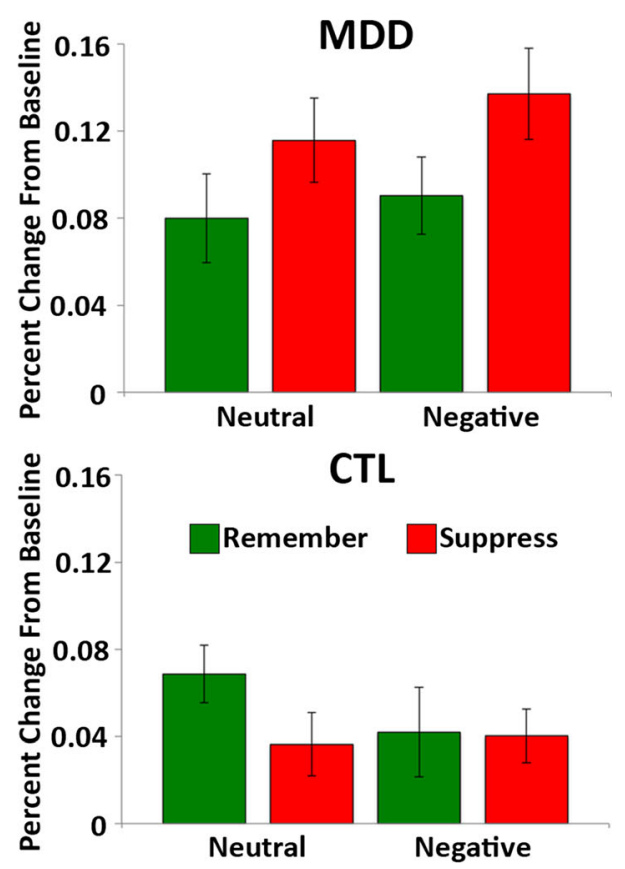

Fig. 3 The MDD group, but the not CTL group, activated the right middle frontal gyrus (MFG) during memory suppression. (A) This cluster (Talairach coordinates: 29 [R], 29 [A], 38 [S]; 1,136 mm , 142 voxels) was identified by a whole-brain analysis looking for regions that showed a group (MDD or CTL) by condition (think or no-think) interaction (limited to neutral trials). (B) The percent signal change was then extracted from this cluster for each condition to further examine this interaction. This revealed that the MDD group recruited this region more during nothink than during think trials, whereas control participants did not. This pattern held for both neutral trials, which had been used to identify the cluster, and for an independent (noncircular) analysis of the negative trials. Error bars indicate standard errors of the means $(S E M \mathrm{~s}) . \mathrm{L}=$ left, $\mathrm{R}=$ right
Looking at neutral trials, the interaction is driven by the MDD group recruiting this region to a greater extent during no-think than during think trials $[F(1,30)=9.25, p<.005]$, whereas the CTL group showed the opposite pattern $[F(1,30)=7.49, p<$ .05]. Interestingly, although this region was identified on the basis of neutral trials alone, a similar pattern was observed in this region during negative trials. Specifically, the MDD group recruited the region more for no-think than for think trials $[F(1$, $30)=6.80, p<.05]$, but the CTL group did not $(F<1)$. This interaction approached significance $[F(1,30)=3.66, p=.06]$, providing weak support for the formulation that the right MFG is recruited during suppression more by depressed than by nondepressed participants, and it does so in an independent (i.e., noncircular) comparison.

Next we examined whether the depressed and nondepressed participants differed in suppression-related activity when the valence of the to-be-suppressed item was manipulated. To do this, we looked for any region that showed a three-way interaction of group, condition, and valence. No regions emerged in this analysis at the whole-brain level; however, given our a priori interest in the hippocampus and amygdala, we conducted the same analysis within a small-volume-corrected search space based on probabilistic atlases of these areas. This analysis revealed clusters in both the right and left hemispheres (Fig. 4A) that spanned both the amygdala and the anterior portion of the hippocampus. To further investigate this three-way interaction, we extracted the time courses from a mask combining the two clusters (the locations were similar in both hemispheres, as was the ordering of the conditions). This analysis revealed that the MDD group modulated activity in this region, as evidenced by decreased activity during no-think relative to think trials, significantly for neutral items $[F(1,30)=10.69, p<.005]$, but not for negative items $(F<1)$. Control participants showed significant modulation for negative items $[F(1,30)=4.06, p=.05]$, but not for neutral items $[F(1,30)=1.62, p=.21]$. Importantly, however, the two-way interaction between condition and valence within each group was not significant for either MDDs $[F(1$, $30)=1.94, p=.17]$ or control participants $(F<1)$.

\section{Discussion}

The present experiment was the first fMRI study to investigate whether and how depressed individuals differ from their 
A
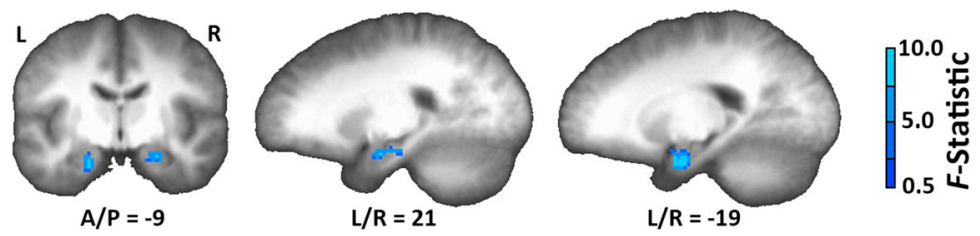

B

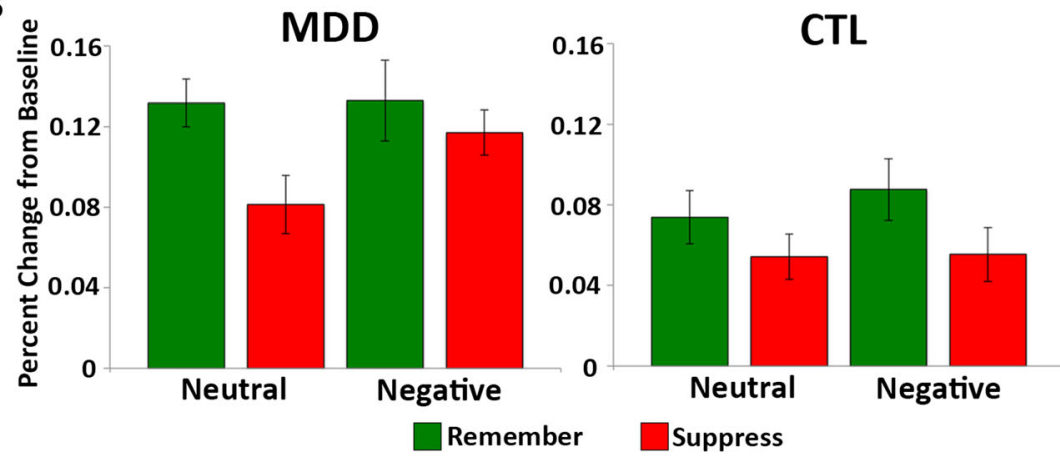

Fig. 4 Modulation of the targets of memory control differs across depression statuses and valences. (A) Using a small-volume correction, a three-way interaction between group, valence, and condition was identified in clusters that encompassed the amygdala and anterior hippocampus in both the right hemisphere (Talairach coordinates: $21[\mathrm{R}],-9[\mathrm{P}],-$ 14 [I]; $824 \mathrm{~mm}^{3}, 103$ voxels) and the left hemisphere (Talairach coordinates: -19 [L], $-5[\mathrm{P}],-18[\mathrm{I}] ; 704 \mathrm{~mm}^{3}, 88$ voxels). (B) The percent signal change was then extracted from a combined bilateral hippocampal-amygdala cluster for each condition, to further examine this interaction. This revealed that the MDD group showed the typical suppressionrelated down-regulation of this region during neutral trials, but not during negative trials. The CTL group showed the opposite pattern, with successful down-regulation for negative items. Error bars indicate standard errors of the means $(S E M \mathrm{~s}) . \mathrm{L}=$ left, $\mathrm{R}=$ right nondepressed counterparts in suppressing unwanted memories. Although we did not observe the expected behavioral impairment in memory suppression for MDD participants, we did find indications in the neuroimaging data concerning how they achieved memorial control. First, depressed individuals were more likely than controls to recruit the right MFG when required to suppress a memory. Second, when we considered the valence of the to-be-suppressed information, the MDD and CTL groups differed in how they modulated activity in the targets of memorial control, specifically the amygdala and hippocampus. These findings point to potential differences between depressed and nondepressed individuals that expand on prior work documenting deficits in inhibitory control in depressed individuals engaged in WM tasks (see Gotlib \& Joormann, 2010).

Researchers have consistently reported that lateral prefrontal cortex (PFC) is engaged during memory suppression (Anderson, 2004; Benoit \& Anderson, 2012; Benoit et al., 2015; Butler \& James, 2010; Depue et al., 2007; Gagnepain et al., 2014; Levy \& Anderson, 2012). This activation often spans both the ventral and dorsal aspects: the inferior frontal gyrus and MFG, respectively. Investigators have generally interpreted these lateral PFC activations as reflecting control processes that are engaged to prevent the unwanted memory from entering awareness (see, e.g., Anderson \& Hanslmayr, 2014; Anderson \& Levy, 2009). Although we found evidence broadly consistent with this general pattern in both the depressed and nondepressed groups, we observed engagement of a specific region within the right MFG that was specific to depressed individuals. Interestingly, this region appears to be anterior and superior to the right-MFG activations that are often seen in univariate contrasts in nondepressed participants. One possibility is that this is a distinct region that is recruited by depressed participants to suppress unwanted memories. Another possibility, which is not mutually exclusive of the first, is that the difference could reflect differential use of suppression strategies by the two groups. Participants in the TNT task report using a wide range of strategies (e.g., thinking of diversionary thoughts or attempting to let their mind go blank; see Levy \& Anderson, 2008), and when participants are instructed to use different strategies, we observe differences in the recruitment of specific prefrontal regions (Benoit \& Anderson, 2012). Benoit and Anderson found that participants selectively recruited a region near this area when they engaged in a direct suppression strategy in which they attempted to stop retrieval without generating alternative thoughts. Because in this study we did not instruct participants to use any specific strategy or ask them to report which strategies they used, we do not know whether the two groups used similar strategies to complete the task. One surprising aspect of this finding is that it reflects increased activity in MDD participants, whereas we predicted that PFC should be hypoactive for these individuals. In retrospect, however, we note that there have been widespread observations of heightened PFC recruitment in depression (e.g., Bär et al., 2007; Diener et al., 2012; Grimm et al., 2008; Harvey et al., 2005; Wagner et al., 2006; Walter, Wolf, Spitzer, \& Vasic, 2007). Interestingly, Harvey et al. 2005 suggested that this 
hyperactivity is most likely to be observed when behavioral performance is matched to healthy controls, as was the case here, suggesting that this is a form of compensatory recruitment (e.g., perhaps due to strategy differences, as suggested above). Further research will be needed to replicate this unexpected pattern and to gain greater leverage on what this region contributes during the task.

In addition to increased PFC activity during suppression, it is also typical to observe decreased activity in the medial temporal lobes (Anderson, 2004; Benoit \& Anderson, 2012; Benoit et al., 2015; Depue et al., 2007; Gagnepain et al., 2014; Levy \& Anderson, 2012). This finding is often interpreted as indicating that the medial temporal lobes are a target of frontal cognitive control, and that their activation is down-regulated, which results in an override of their role in recovering information from long-term memory (e.g., Anderson \& Hanslmayr, 2014; Anderson \& Levy, 2009). In addition, there is evidence that when participants attempt to suppress negatively valenced information, they also down-regulate activity in the amygdala (Butler \& James, 2010; Depue et al., 2007). In the present study, we observed a cluster in both hemispheres that included the amygdala as well as the hippocampus and that activated differentially in the depressed and nondepressed groups to the different valences. Across all combinations of valence and group, think activity in this region was numerically greater than no-think activity, consistent with prior evidence that these regions are modulated during suppression. The three-way interaction appears to reflect the differential effectiveness of this modulation between the groups for the two different valence conditions: Specifically, nondepressed participants were relatively more successful at modulating this region when suppressing negative materials, and depressed participants were relatively more successful when suppressing neutral stimuli. We expected that depressed individuals would have the most difficulty suppressing memories of negative experiences, so this pattern is broadly consistent with our predictions. $^{2}$

It is interesting to note that we did not observe any significant behavioral differences between the depressed and nondepressed participants. This may not be surprising, given that other studies have also failed to observe significant SIF impairments in depressed and dysphoric populations (Hertel \& Calcaterra, 2005; Joormann et al., 2009). Interestingly, the studies that have reported no significant differences in SIF as a function of depression status have tended to have smaller sample sizes than the studies that have reported significant differences, a concern that is also relevant to the present study.

\footnotetext{
${ }^{2}$ It should be noted that the two-way interaction between valence and condition in this region was not significant for the MDDs, so we cannot say that individuals in the MDD group modulated this region more for neutral than for negative items.
}

Interestingly, we did observe numerically greater SIF in CTLs than in MDDs on the IP test $(7.3 \%$ vs. $5.0 \%$, respectively, collapsed across valences), which has been argued to be more sensitive than the SP test for assessing inhibitory control ability (Anderson \& Levy, 2011). When considering all of the behavioral evidence, it appears that the inhibitory impairments in this paradigm may be relatively modest. Similarly, despite our emphasis on the regions that differed between controls and depressed individuals, there was considerable similarity in the general patterns of brain activity observed in these two groups of participants, which is again consistent with the position that differences on this task due to suppression are subtle. ${ }^{3}$ That does not mean, however, that any differences would be unimportant for increasing our understanding of depression. Indeed, even small impairments in the moment-to-moment regulation of retrieval could compound dramatically, given the many retrieval opportunities that are present in everyday life. For example, we know that retrieval itself acts as a powerful learning event (see, e.g., Karpicke, 2012); thus, each instance of failed retrieval suppression could lead to that unwanted thought being encoded better in long-term memory and, in MDDs, contributing to negative schemas that have been posited to perpetuate the negative cognitions that are fundamental to this disorder (Beck, 1976). It is also important to note that, consistent with prior studies using this paradigm (Hertel \& Gerstle 2003; Joormann et al., 2005), we did not observe any evidence of diminished forgetting of negative material by the depressed individuals. Although individual null results can be inconclusive, the repeated failure to confirm this prediction seems to be at odds with other evidence suggesting that depressed individuals have particular difficulty suppressing negative stimuli (for a review, see Gotlib \& Joormann, 2010). Interestingly, all of the extant TNT studies have used verbal stimuli, which may not produce as strong an affective modulation as contextually richer stimuli (e.g., photographs). Perhaps future studies could use valenced picture stimuli (see Depue, Banich, \& Curran, 2006; Depue et al., 2007) with these populations to further explore this issue.

In closing, our findings suggest that depressed and nondepressed individuals differ in their brain activity when they are asked to suppress memory retrieval. A fruitful next step would be to further explore the regions implicated in this study, to elucidate their mechanistic contributions to this task. This area of inquiry could also benefit from a behavioral study with a larger sample, in order to better characterize the magnitude

\footnotetext{
${ }^{3}$ We did not, however, examine functional or effective connectivity between regions. Thus, it is possible that despite similar univariate patterns, connectivity patterns might differ between groups. Future research should directly assess the relations between brain connectivity and suppression.
} 
and consistency of depression-associated behavioral impairments in this task. It would also be instructive to examine the brain activity as depressed individuals are provided with an explicit strategy to perform the suppression task. Previous research has suggested that "aided" strategies, in which an alternative diversionary thought is used, can help depressed individuals overcome deficits in SIF (Hertel \& Calcaterra, 2005; Joormann et al., 2009), and can also change the pattern of brain activity in nondepressed individuals (Benoit \& Anderson, 2012; Bergström, de Fockert, \& RichardsonKlavehn, 2009). Finally, this line of research could help bridge two features that are often discussed as distinct aspects of depression: impaired inhibitory control and rumination. As we discussed earlier, most of the evidence for impaired inhibition in depression has focused on how items enter or are removed from WM. This has obvious implications for how individuals might encode new experiences, but it tells us relatively little about how they deal with existing long-term memories of their own experiences, which are precisely the kinds of events about which depressed individuals are likely to ruminate. Indeed, in an unselected sample of undergraduate students, levels of rumination were found to be related to impaired suppression-induced forgetting, even when controlling for deliberate reprocessing, which is related to both rumination and suppression (Fawcett et al., 2015; Joormann \& Tran, 2009). Furthermore, Hertel and Gerstle (2003) found that dysphoric individuals who were high in rumination exhibited reduced SIF as compared to lower-ruminating dysphoric individuals. These findings implicate rumination as a key component of SIF abnormalities in MDD. Gaining a better understanding of how depressed individuals struggle to control access to memory will not only help elucidate the core features of depression, but may be relevant for other disorders that also involve difficulty controlling unwanted thoughts (e.g., Brewin, Gregory, Lipton, \& Burgess, 2010; Catarino, Kupper, Werner-Seidler, Dalgleish, \& Anderson, 2015; Depue, Burgess, Bidwell, Willcutt, \& Banich, 2010; Koob \& Volkow 2009; Marzi, Regina, \& Righi, 2014; Verfaellie \& Vasterling, 2009).

\begin{abstract}
Author note This study was supported by NSF Integrative Graduate Education and Research Traineeship Recipient Award No. 0801700, NSF Graduate Research Fellowship Program (GRFP) DGE-1147470, and NIMH Neuroscience Research Training Award No. T32 MH020016, to M.D.S.; by NIMH Grant No. R01-MH59259 to I.H.G.; and UK Medical Research Council Grant No. MC-A060-5PR00 to M.C.A.
\end{abstract}

Open Access This article is distributed under the terms of the Creative Commons Attribution 4.0 International License (http:// creativecommons.org/licenses/by/4.0/), which permits unrestricted use, distribution, and reproduction in any medium, provided you give appropriate credit to the original author(s) and the source, provide a link to the Creative Commons license, and indicate if changes were made.

\section{References}

Anderson, M. C. (2004). Neural systems underlying the suppression of unwanted memories. Science, 303, 232-235.

Anderson, M. C., \& Green, C. (2001). Suppressing unwanted memories by executive control. Nature, 410, 366-369.

Anderson, M. C., \& Hanslmayr, S. (2014). Neural mechanisms of motivated forgetting. Trends in Cognitive Sciences, 18, 279-292. doi:10.1016/j.tics.2014.03.002

Anderson, M. C., \& Huddleston, E. (2011). Towards a cognitive and neurobiological model of motivated forgetting. In R. F. Belli (Ed.), True and false recovered memories (Vol. 58, pp. 53-120). New York, NY: Springer.

Anderson, M. C., \& Levy, B. J. (2009). Suppressing unwanted memories. Current Directions in Psychological Science, 18, 189-194.

Anderson, M. C., \& Levy, B. J. (2011). On the relationship between interference and inhibition in cognition. In A. Benjamin (Ed.), Successful remembering and successful forgetting: A festschrift in honor of Robert A. Bjork (pp. 107-132). New York, NY: Psychology Press.

Anderson, M. C., \& Spellman, B. A. (1995). On the status of inhibitory mechanisms in cognition: Memory retrieval as a model case. Psychological Review, 102, 68-100. doi:10.1037/0033-295 X.102.1.68

Bär, K.-J., Wagner, G., Koschke, M., Boettger, S., Boettger, M. K., Schlösser, R., \& Sauer, H. (2007). Increased prefrontal activation during pain perception in major depression. Biological Psychiatry, 62, 1281-1287.

Beck, A. T. (1976). Cognitive therapy and the emotional disorders. New York, NY: International Universities Press.

Beck, A. T., Rush, A. J., Shaw, B. F., \& Emery, G. (1979). Cognitive therapy of depression. New York, NY: Guilford Press.

Benoit, R. G., \& Anderson, M. C. (2012). Opposing mechanisms support the voluntary forgetting of unwanted memories. Neuron, 76, 450-460.

Benoit, R. G., Hulbert, J. C., Huddleston, E., \& Anderson, M. C. (2015). Adaptive top-down suppression of hippocampal activity and the purging of intrusive memories from consciousness. Journal of Cognitive Neuroscience, 27, 96-111.

Bergström, Z. M., de Fockert, J. W., \& Richardson-Klavehn, A. (2009). ERP and behavioural evidence for direct suppression of unwanted memories. NeuroImage, 48, 726-737.

Bradley, M. M., \& Lang, P. J. (1999). Affective Norms for English Words (ANEW): Stimuli, instruction manual and affective ratings (Technical Report No. C-1). Gainesville, FL: University of Florida, Center for the Study of Emotion and Attention.

Brewin, C. R., Gregory, J. D., Lipton, M., \& Burgess, N. (2010). Intrusive images in psychological disorders: Characteristics, neural mechanisms, and treatment implications. Psychological Review, 117, 210-232.

Butler, A. J., \& James, K. H. (2010). The neural correlates of attempting to suppress negative versus neutral memories. Cognitive, Affective, \& Behavioral Neuroscience, 10, 182-194. doi:10.3758 /CABN.10.2.182

Catarino, A., Kupper, C. S., Werner-Seidler, A., Dalgleish, T., \& Anderson, M. C. (2015). Failing to forget: Inhibitory-control deficits compromise memory suppression in posttraumatic stress disorder. Psychological Science, 26, 604-616.

Chrastil, E. R., Sherrill, K. R., Hasselmo, M. E., \& Stern, C. E. (2015). There and back again: Hippocampus and retrosplenial cortex track homing distance during human path integration. Journal of Neuroscience, 35, 15442-15452. doi:10.1523/JNEUROSCI.120915.2015

Cohen, M. S. (1997). Parametric analysis of fMRI data using linear systems methods. NeuroImage, 6, 93-103. 
Cox, R. W. (1996). AFNI: Software for analysis and visualization of functional magnetic resonance neuroimages. Computers and Biomedical Research, 29, 162-173.

Dale, A. M. (1999). Optimal experimental design for event-related fMRI. Human Brain Mapping, 8, 109-114.

Depue, B. E., Banich, M. T., \& Curran, T. (2006). Suppression of emotional and nonemotional content in memory: Effects of repetition on cognitive control. Psychological Science, 17, 441-447.

Depue, B. E., Burgess, G. C., Bidwell, L. C., Willcutt, E. G., \& Banich, M. T. (2010). Behavioral performance predicts grey matter reductions in the right inferior frontal gyrus in young adults with combined type ADHD. Psychiatry Research: Neuroimaging, 182, 231237.

Depue, B. E., Curran, T., \& Banich, M. T. (2007). Prefrontal regions orchestrate suppression of emotional memories via a two-phase process. Science, 317, 215-219.

Diener, C., Kuehner, C., Brusniak, W., Ubl, B., Wessa, M., \& Flor, H. (2012). A meta-analysis of neurofunctional imaging studies of emotion and cognition in major depression. NeuroImage, 61, 677-685.

Eickhoff, S. B., Stephan, K. E., Mohlberg, H., Grefkes, C., Fink, G. R., Amunts, K., \& Zilles, K. (2005). A new SPM toolbox for combining probabilistic cytoarchitectonic maps and functional imaging data. NeuroImage, 25, 1325-1335.

Fawcett, J. M., Benoit, R. G., Gagnepain, P., Salman, A., Bartholdy, S., Bradley, C., . . . Anderson, M. C. (2015). The origins of repetitive thought in rumination: Separating cognitive style from deficits in inhibitory control over memory. Journal of Behavior Therapy and Experimental Psychiatry, 47, 1-8. doi:10.1016/j.jbtep.2014.10.009

First, M. B., Dibbon, M., Spitzer, R. L., \& Williams, J. B. (2004). Structured Clinical Interview for DSM-IV-TR. Washington, DC: American Psychiatric Association.

Friston, K. J., Holmes, A. P., Worsley, K. J., \& Poline, J. P. (1995). Statistical parametric maps in functional imaging: A general linear approach. Human Brain Mapping, 2, 189-210.

Gagnepain, P., Henson, R. N., \& Anderson, M. C. (2014). Suppressing unwanted memories reduces their unconscious influence via targeted cortical inhibition. Proceedings of the National Academy of Sciences, 111, E1310-E1319.

Glover, G. H., \& Law, C. S. (2001). Spiral-in/out BOLD fMRI for increased SNR and reduced susceptibility artifacts. Magnetic Resonance in Medicine, 46, 515-522.

Goeleven, E., De Raedt, R., Baert, S., \& Koster, E. H. W. (2006). Deficient inhibition of emotional information in depression. Journal of Affective Disorders, 93, 149-157.

Gotlib, I. H., \& Joormann, J. (2010). Cognition and depression: Current status and future directions. Annual Review of Clinical Psychology, 6, 285-312. doi:10.1146/annurev.clinpsy.121208

Gotlib, I. H., Yue, D. N., \& Joormann, J. (2005). Selective attention in dysphoric individuals: The role of affective interference and inhibition. Cognitive Therapy Research, 29, 417-432.

Grimm, S., Beck, J., Schuepbach, D., Hell, D., Boesiger, P., Bermpohl, F., . . Northoff, G. (2008). Imbalance between left and right dorsolateral prefrontal cortex in major depression is linked to negative emotional judgment: An fMRI study in severe major depressive disorder. Biological Psychiatry, 63, 369-376. doi:10.1016/j. biopsych.2007.05.033

Harvey, P.-O., Fossati, P., Pochon, J.-B., Levy, R., Lebastard, G., Lehéricy, S., . . . Dubois, B. (2005). Cognitive control and brain resources in major depression: An fMRI study using the $n$-back task. NeuroImage, 26, 860-869.

Hertel, P. T., \& Calcaterra, G. (2005). Intentional forgetting benefits from thought substitution. Psychonomic Bulletin \& Review, 12, 484-489. doi:10.3758/BF03193792

Hertel, P. T., \& Gerstle, M. (2003). Depressive deficits in forgetting. Psychological Science, 14, 573-578.
Hertel, P. T., \& Mahan, A. (2008). Depression-related differences in learning and forgetting responses to unrelated cues. Acta Psychologica, 127, 636-644. doi:10.1016/j.actpsy.2007.11.004

Hulbert, J. C., Henson, R. N., \& Anderson, M. C. (2016). Inducing amnesia through systemic suppression. Nature Communications, 7(11003), 1-9. doi:10.1038/ncomms 11003

Ingram, R. E. (1984). Toward an information-processing analysis of depression. Cognitive Therapy Research, 8, 443-477.

Joormann, J. (2004). Attentional bias in dysphoria: The role of inhibitory processes. Cognition and Emotion, 18, 125-147.

Joormann, J., \& Gotlib, I. H. (2008). Updating the contents of working memory in depression: Interference from irrelevant negative material. Journal of Abnormal Psychology, 117, 182-192.

Joormann, J., Hertel, P. T., Brozovich, F., \& Gotlib, I. H. (2005). Remembering the good, forgetting the bad: Intentional forgetting of emotional material in depression. Journal of Abnormal Psychology, 114, 640-648. doi:10.1037/0021-843X.114.4.640

Joormann, J., Hertel, P. T., LeMoult, J., \& Gotlib, I. H. (2009). Training forgetting of negative material in depression. Journal of Abnormal Psychology, 118, 34-43.

Joormann, J., Nee, D. E., Berman, M. G., Jonides, J., \& Gotlib, I. H. (2010). Interference resolution in major depression. Cognitive, Affective, \& Behavioral Neuroscience, 10, 21-33. doi:10.3758 /CABN.10.1.21

Joormann, J., \& Tran, T. B. (2009). Rumination and intentional forgetting of emotional material. Cognition and Emotion, 23, 1233-1246.

Karpicke, J. D. (2012). Retrieval-based learning: Active retrieval promotes meaningful learning. Current Directions in Psychological Science, 21, 157-163.

Kircanski, K., Joormann, J., \& Gotlib, I. H. (2012). Cognitive aspects of depression. Wiley Interdisciplinary Reviews: Cognitive Science, 3, 301-313.

Koob, G. F., \& Volkow, N. D. (2009). Neurocircuitry of addiction. Neuropsychopharmacology, 35, 217-238.

Levens, S. M., \& Gotlib, I. H. (2010). Updating positive and negative stimuli in working memory in depression. Journal of Experimental Psychology: General, 139, 654-664.

Levy, B. J., \& Anderson, M. C. (2008). Individual differences in the suppression of unwanted memories: The executive deficit hypothesis. Acta Psychologica, 127, 623-635. doi:10.1016/j. actpsy.2007.12.004

Levy, B. J., \& Anderson, M. C. (2012). Purging of memories from conscious awareness tracked in the human brain. Journal of Neuroscience, 32, 16785-16794.

Marzi, T., Regina, A., \& Righi, S. (2014). Emotions shape memory suppression in trait anxiety. Frontiers in Psychology, 4(1001), 1-10. doi:10.3389/fpsyg.2013.01001

Mathews, A., \& MacLeod, C. (2005). Cognitive vulnerability to emotional disorders. Annual Review of Clinical Psychology, 1, 167-195. doi:10.1146/annurev.clinpsy.1.102803.143916

Matt, G. E., Vázquez, C., \& Campbell, W. K. (1992). Mood-congruent recall of affectively toned stimuli: A meta-analytic review. Clinical Psychology Review, 12, 227-255.

Nolen-Hoeksema, S. (2000). The role of rumination in depressive disorders and mixed anxiety/depressive symptoms. Journal of Abnormal Psychology, 109, 504-511.

Paz-Alonso, P. M., Bunge, S. A., Anderson, M. C., \& Ghetti, S. (2013). Strength of coupling within a mnemonic control network differentiates those who can and cannot suppress memory retrieval. Journal of Neuroscience, 33, 5017-5026. doi:10.1523/JNEUROSCI.345912.2013

Talairach, J., \& Tournoux, P. (1998). Co-planar stereotaxic atlas of the human brain: 3-dimensional proportional system. An approach to cerebral imaging. Stuttgart, Germany: Thieme. 
Teasdale, J. D. (1983). Negative thinking in depression: Cause, effect, or reciprocal relationship? Advances in Behaviour Research and Therapy, 5, 3-25.

Tulving, E., \& Thomson, D. M. (1973). Encoding specificity and retrieval processes in episodic memory. Psychological Review, 80, 352-373. doi: $10.1037 / \mathrm{h} 0020071$

Verfaellie, M., \& Vasterling, J. J. (2009). Memory in PTSD: A neurocognitive approach. In P. J. Shiromani, T. M. Keane, \& J. E. LeDoux (Eds.), Post-traumatic stress disorder: Basic science and clinical practice (pp. 105-130). New York, NY: Humana Press. doi:10.1007/978-1-60327-329-9 5

Wagner, G., Sinsel, E., Sobanski, T., Köhler, S., Marinou, V., Mentzel, H.J., . . S Schlösser, R. G. (2006). Cortical inefficiency in patients with unipolar depression: An event-related fMRI study with the Stroop task. Biological Psychiatry, 59, 958-965. doi:10.1016/j. biopsych.2005.10.025

Walter, H., Wolf, R. C., Spitzer, M., \& Vasic, N. (2007). Increased left prefrontal activation in patients with unipolar depression: An eventrelated, parametric, performance-controlled fMRI study. Journal of Affective Disorders, 101, 175-185.

Williams, J. M. G., Watts, F., MacLeod, C., \& Mathews, A. (1997). Cognitive psychology and emotional disorders. Chichester, UK: Wiley.

Woo, C.-W., Krishnan, A., \& Wager, T. D. (2014). Cluster-extent based thresholding in fMRI analyses: Pitfalls and recommendations. NeuroImage, 91, 412-419.

Xiong, J., Gao, J. H., Lancaster, J. L., \& Fox, P. T. (1995). Clustered pixels analysis for functional MRI activation studies of the human brain. Human Brain Mapping, 3, 287-301. 